\title{
Antioxidant Potential, Phenolics Content and Antimicrobial Attributes of Selected Medicinal Plants
}

\author{
Ali Abbas ${ }^{1,2}$, Bushra Sultana ${ }^{1}$, Anwaar Hussain ${ }^{3}$, Farooq Anwar $^{4} *$ and \\ Naveed Ahmad ${ }^{5}$ \\ ${ }^{1}$ Department of Chemistry, University of Agriculture, Faisalabad, Pakistan. \\ ${ }^{2}$ Department of Chemistry, Govt. Post Graduate Taleem ul Islam College, Chenab Nagar, Chiniot, Pakistan. \\ ${ }^{3}$ Faisalabad Medical University, Faisalabad, Pakistan. \\ ${ }^{4}$ Institute of Chemistry, University of Sargodha, Sargodha, Pakistan. \\ ${ }^{5}$ Department of Chemistry, Division of Science and Technology, University of Education, Lahore, Pakistan. \\ *Corresponding Author Email: fqanwar@yahoo.com \\ Received 11 August 2020, Revised 28 November 2021, Accepted 08 December 2021
}

\begin{abstract}
The bioactive extracts recovered from Curcuma longa (stem), Mentha aquatica (stem and leaves), Emblica officinalis (fruits), Nigella sativa (seeds), and Glycyrrhiza glabra (stem) using methanol and ethanol, were appraised for antioxidant (total flavonoid contents, total phenolic contents, DPPH free radical scavenging ability, inhibition of linoleic acid peroxidation and reducing power) and anti microbial attributes. Total phenolics $(16.89 \pm 0.18-25.06 \pm 0.31 \mathrm{~g} \mathrm{GAE} / 100 \mathrm{~g})$ and total flavonoids $(1.96 \pm 0.07-13.54 \pm 0.18 \mathrm{CE} \mathrm{g} / 100 \mathrm{~g})$ contents of aqueous methanol extracts of tested plant materials were significantly $(p<0.05)$ lower than that of aqueous ethanol extracts $(13.87 \pm$ $0.12-28.63 \pm 0.34 \mathrm{~g} \mathrm{GAE} / 100 \mathrm{~g})$ and $(2.20 \pm 0.10-8.71 \pm 0.24 \mathrm{CE} / 100 \mathrm{~g})$, respectively. The percent inhibition of linoleic acid per oxidation by crude ethanol extracts of plants was in the range of $48.72 \pm 1.24-70.79 \pm 1.57$ and crude methanol extract $35.90 \pm 1.28-61.54 \pm$ 2.14, while the range of DPPH free radical scavenging activity of ethanol extracts was $(58.36 \pm 1.98-80.55 \pm 3.07)$ and methanol extracts $(39.55 \pm 1.52-79.64 \pm 2.33)$. The reducing power of the tested extracts obtained by ethanol (at the concentration of 10 $\mathrm{mg} / \mathrm{mL}$ ) ranged $1.11 \pm 0.12-1.53 \pm 0.18$ while for methanol extracts $0.98 \pm 0.11-1.39 \pm 0.12$. Among the attributes analyzed, total phenolics, total flavonoids, and DPPH free scavenging activity were found to be varied significantly in all the tested medicinal plants. The extracts from all plants showed good antimicrobial potential against a penal of bacteria, including $E$. coli, $P$. multocida and S. aureus, and fungi including A. niger, A. flavus, A. alternate, and G. lucidium. Overall, the tested samples were found to be a good source of natural antioxidant and antimicrobial agents and thus can be explored for potential functional food and nutra-pharmaceutical applications.
\end{abstract}

Keywords: Medicinal flora, Antioxidant components, Solvent extraction, Colorimetric assays, Antimicrobial agents

\section{Introduction}

It is widely believed that antioxidants are the substances that have the ability to defend the body against oxidative damage that occurs due to free radicals [1]. In the food industry, antioxidants have been used to stop or slow down the process of deterioration and enhance the shelf-life of foods, especially those containing polyunsaturated fatty acids [2]. Based on ethno-medicinal knowledge, many plants have been checked and employed for 
the treatment of various diseases in folk medicines. Medicinal benefits of plants can be ascribed to the existence of a variety of phytochemicals so-called bioactive, with various biological and pharmacological activities [3-5]. Besides other bioactives, medicinal plants are also known as the richest source of natural phenolics, which exhibit free radical scavenging and antimicrobial potential $[3,6]$.

Pakistan is blessed with a wide variety of medicinal flora, including herbs, shrubs, and trees with functional food/ nutraceutical potential and physiological benefits; several of such species are employed in the local/folk system of medicine for the treatment of different ailments [4-7].

Of the indigenous medicinal plant, typically, Mentha aquatica is an important organic herb from the family "Lamiaceae" and called "water mint". Its extract, being a potential source of natural antioxidants, can reduce diphenyl picrylhydrazyl (DPPH) radicals in a concentration dependent manner [8]. Another important herb, Curcuma longa from the "Zingiberaceae" family, also called "Turmeric" has anti-carcinogenic potential due to the presence of antioxidants and freeradical scavenging agents [9]. Emblica officinalis belonging to the "Phyllanthaceae" family with the common name "Gorse berry" is also popular due to its medicinal and antioxidant effects [10]. Similarly, another local species Glycyrrhiza glabra, from a family of "Fabaceae" is valued for its antioxidant potential due to the presence of isoflavonoids and other flavonoid derivatives [11]. Black cumin (Nigella sativa), a member of "Ranunculaceae", is reported to exhibit DPPH scavenging potential due to the presence of antioxidant compounds [12].

Although many indigenous plants from Pakistani flora possess biological and medicinal potential, the plant materials selected in the present research work are conventionally used as folk medicine for the treatment of various diseases as well as employed in the formulations of different Ayurvedic medicines. So there is a prompt need to evaluate and provide a scientific basis towards elucidating and establishing the medicinal value of these species. Very limited reports are available on the antioxidant and antimicrobial properties of species selected for this study. In particular, the biological attributes of aqueous alcoholic extracts from different parts of selected species such as Mentha aquatica, Glycyrrhiza glabra, Emblica officinalis, Curcuma longa, and Nigella sativa native to Pakistan have not been assessed. Therefore, this research was framed to assess the antioxidant and antimicrobial attributes of aqueous methanol and aqueous ethanol extracts from different parts of the above medicinal plants.

\section{Materials and Methods Samples}

Three different samples of the stem of Curcuma longa (Haldi), stem and leaves for Mentha aquatica (Aabi Podina), stem of Glycyrrhiza glabra (Mulathi), fruits of Emblica officinalis (Amla), and seeds of Nigella sativa (Kalonji) were obtained from Department of Horticulture, University of Agriculture Faisalabad (UAF), Punjab, Pakistan, and the specimens were authenticated by Department of Botany, University of Agriculture, Faisalabad. The samples were washed with deionized water and dried in a well-ventilated laboratory under ambient temperature conditions.

\section{Reagents and Chemicals}

BHT (butylated hydroxytoluene) (99\%), Linoleic acid, gallic acid, catechin, DPPH (Diphenyl picrylhydrazyl), and Folin- 
Ciocalteu reagent with the concentration of 2 $N$ were bought from Sigma Chemicals Co. (USA). The additional chemicals used in this research were obtained from Merck (Germany) in pure form.

\section{Preparation of Extracts}

Dried samples of fruits of Emblica officinalis, stem and leaves of Mentha aquatica, stem of Glycyrrhiza glabra, stem of Curcuma longa, and seeds of Nigella sativa were pulverized to get fine powder with the particle size of 80 mesh using a commercial grinder (West point, France). Ten grams of the powdered samples were extracted with 100 $\mathrm{mL}$ of methanol: water $(80: 20 \mathrm{v} / \mathrm{v})$ solution and ethanol:water $(80: 20 \mathrm{v} / \mathrm{v})$ solution separately using an orbital shaker at room temperature for $8 \mathrm{~h}$, and the insoluble residue was removed by filtration. The residue was again extracted two times using the same amount of fresh solvent, and all the three extracts for each category of solvent were combined. Evaporation of solvent was done using a rotary evaporator (EYELA, Japan) to concentrate the extracts under reduced pressure. These concentrated extracts were used to calculate the percentage yield and kept at $-4{ }^{\circ} \mathrm{C}$ for further experiments.

\section{Antioxidant Activity of Medicinal Plants Extracts \\ Total phenolic contents}

The TPC (total phenolic contents) of the plant extracts were investigated using Folin-Ciocalteu reagent procedure [13]. For this purpose, $50 \mathrm{mg}$ of extract obtained from a plant was mixed with $0.5 \mathrm{~mL}$ of FolinCiocalteu reagent, followed by the addition of $7.5 \mathrm{~mL}$ of de-ionized water. Incubated the mixture for $10 \mathrm{~min}$, then added $1.50 \mathrm{~mL}$ of $20 \%$ aqueous solution of sodium carbonate. Heated the above reaction mixture at $40{ }^{\circ} \mathrm{C}$ in a water bath for $20 \mathrm{~min}$; finally the solution was cooled using an ice bath. The solution turned blue and noted the absorbance at the wavelength of $755 \mathrm{~nm}$ using a spectrophotometer (Hitachi, Japan, U-2001). The result of total phenolic contents was expressed in $\mathrm{mg} /$ gram of gallic acid equivalent of dry weight.

\section{Total flavonoid contents}

The TFC (total flavonoid contents) of plant extracts were measured using the method described by Dewanto et al. [14]. In this method, $0.1 \mathrm{mg}$ of crude extract was combined with $4 \mathrm{~mL}$ water followed by addition of $0.30 \mathrm{~mL} 5 \%(\mathrm{w} / \mathrm{v})$ solution of $\mathrm{NaNO}_{2}$ along with $0.3 \mathrm{~mL} 10 \%(\mathrm{w} / \mathrm{v})$ solution of $\mathrm{AlCl}_{3}$ and $2 \mathrm{~mL} 1 M$ solution of $\mathrm{NaOH}$. Finally, $2.4 \mathrm{~mL}$ distilled $\mathrm{H}_{2} \mathrm{O}$ was added into the reaction mixture and mixed completely. A spectrophotometer was used to record the absorbance at a wavelength of $510 \mathrm{~nm}$, and contents of flavonoids were expressed as $\mathrm{mg} / \mathrm{grams}$ of catechin equivalent of dry weight.

\section{$D P P H \cdot$ free radical scavenging assay}

The scavenging ability of DPPH $(2,2-$ diphenyl-1-picrylhydrazyl) free radical measures the antioxidant capacity of plants extracts [15]. For this purpose, $0.5-100 \mu \mathrm{g} / \mathrm{L}$ of crude extracts obtained from selected plants were mixed with $1.0 \mathrm{~mL}$ of $90 \mu \mathrm{M}$ solution of DPPH then added 95\% methanol to make the volume $4 \mathrm{~mL}$. Butylated hydroxytoluene (BHT) was used as a positive control in this experiment. After the incubation time of 1 hour, the absorbance of the solution was measured at $515 \mathrm{~nm}$. The percentage inhibition of DPPH free radical was measured by the formula given below:

$$
\mathrm{I}(\%)=100 \times(\mathrm{Ab}-\mathrm{As} / \mathrm{Ab})
$$


Here absorbance of control reaction mixture, which contain all he reagents except the sample extracts, was denoted by "Ab" and the absorbance of the tested extract was given by “As".

\section{Inhibition of linoleic acid peroxidation}

The percent inhibition of linoleic acid peroxidation was assessed by the method previously reported by Iqbal et al. [16]. In this method, $5 \mathrm{mg}$ of crude extract was mixed with $0.13 \mathrm{~mL}$ of linoleic acid followed by $10 \mathrm{~mL}$ of absolute ethanol (99.8\%) and $10 \mathrm{~mL}$ of sodium phosphate buffer of concentration $0.2 \mathrm{M}$ and $\mathrm{pH}$ 7. Finally, distilled $\mathrm{H}_{2} \mathrm{O}$ was mixed in the above reaction mixture to make the volume up to $25 \mathrm{~mL}$ and then incubated the solution for 360 hours at $40{ }^{\circ} \mathrm{C}$. The oxidation strength was noted by measuring the peroxide value using thiocyanate method as reported earlier [17]. During this process, 75\% ethanol solution in water $(10 \mathrm{~mL}), 30 \%$ solution of ammonium thiocyanate in water $(0.2 \mathrm{~mL}), 20 \mathrm{mM}$ solution of ferrous chloride in $3.5 \% \mathrm{HCl}(0.2 \mathrm{~mL})$, and $0.2 \mathrm{~mL}$ sample solution was mixed to the pre-incubated reaction mixture. Stirred the solution for 3 minutes, and absorbance was noted at the wavelength of $500 \mathrm{~nm}$ using a spectrophotometer. A control reaction mixture was also checked under the same experimental condition but without extracts. BHT, a synthetic antioxidant, was used as a positive control. The inhibition capacity of linoleic acid peroxidation in terms of percentage was measured using the formula:

$\%=100-[($ increase in absorbance (sample) $/$ increase in absorbance (control) $\times 100]$

\section{Reducing power}

This antioxidant assay of plant derived extracts was accessed by using the method written by Sultana et al. [18]. Different amount of extract obtained from plants ranging from 2.5 to $10.0 \mathrm{mg}$ was combined with $5.0 \mathrm{~mL}$ of phosphate buffer with concentration $0.2 \mathrm{M}$ having pH 6.6 and $5.0 \mathrm{~mL}$ of $1.0 \%$ solution of potassium ferricyanide in water. Incubated the above reaction mixture for about 20 minutes at $50{ }^{\circ} \mathrm{C}$, then added $5 \mathrm{~mL}$ of $10 \%$ solution trichloroacetic acid. Centrifuged the reaction mixture at $5{ }^{\circ} \mathrm{C}$ for 10 minutes at the speed of $80 \mathrm{rpm}$ in a low temperature centrifuge machine (Kokusan Denki, Japan, CHM-17). Took $5.0 \mathrm{~mL}$ of the upper layer, diluted it with $5.0 \mathrm{~mL}$ of distilled $\mathrm{H}_{2} \mathrm{O}$, then mixed with 1.0 $\mathrm{mL}$ of freshly prepared $0.1 \%$ solution of ferric chloride in water. Noted the absorbance of the reaction mixture at $700 \mathrm{~nm}$.

\section{Antimicrobial Activity}

All the extracts of selected medicinal plants were tested separately for antimicrobial activity against three bacterium strains $E$. coli, $P$. multocida and $S$. aureus and four fungal stains A. niger, A. flavus, A. alternata, and $G$. lucidium. All these micro-organism including bacteria and fungus, were procured from Biochemistry Department of University of Agriculture, Faisalabad, Pakistan. For the optimum growth of selected micro-organisms, the bacteria used in the present research work were cultured at an optimum temperature of $37{ }^{\circ} \mathrm{C}$ on nutrient agar (Oxoid, UK), and the fungus was cultured at an optimum temperature of $30{ }^{\circ} \mathrm{C}$ on potato dextrose agar (Oxoid, UK).

\section{Disc diffusion method}

The selected plant extracts were subjected to analyze the antimicrobial activity using the disc diffusion method [19]. For this purpose, small discs with $6 \mathrm{~mm}$ of diameter were dipped with sample extract $(50 \mu \mathrm{L})$ and placed on tested micro-organism previously inoculated on the agar plate. For comparative results, Rifampicin and Fluconazol with the 
amount of $30 \mu \mathrm{g} /$ disc were taken as positive reference standard drugs for bacterial and fungal strain, respectively. The whole setup was incubated for $24 \mathrm{~h}$ at $37^{\circ} \mathrm{C}$ for bacterial growth and 3 days at $25^{\circ} \mathrm{C}$ for fungal growth. The antimicrobial activity of tested extracts was accessed by measuring the zone of inhibition of microorganism growth in milli meters.

\section{Micro dilution broth assay}

The MIC (minimum inhibitory concentration) value of plant extracts was checked using the microdilution broth method previously reported [19]. On a 96-well microtiter plate, a sequence of dilution of plant extracts was placed, followed by two controls, i.e., growth control and sterility control. For bacterial strain $160 \mu \mathrm{L}$ of NB and for fungal strain SBD were combined with 20 $\mu \mathrm{L}$ of tested solution into the microplates. Then inoculated the plates with the suspension of standard micro-organism $\left(20 \mu \mathrm{L}\right.$ of $5 \times 10^{5}$ $\mathrm{CFU} / \mathrm{mL}$ ). Incubated the plates for $24 \mathrm{~h}$ at $37^{\circ} \mathrm{C}$ for the bacterial strain and $48 \mathrm{~h}$ at $28^{\circ} \mathrm{C}$ for fungal strain. The reference compound Rifampicin was used as an antibacterial and Fluconazole as an antifungal agent. At the bottom of the well, white pellets were produced, which indicated the growth, and the results were reported in the form of MIC value $(\mathrm{mg} / \mathrm{mL})$.

\section{Statistical Analysis}

Each experiment was performed three times to compute three measurements (replicates). The experimental data were analyzed statistically using a statistical tool/software STATISTICA 5.5 (USA). The significant difference between different samples was given by a probability value of $p \leq 0.05$. The whole data was recorded as mean values \pm SD (Standard deviation) for triplicate determinations [20].
Results and Discussion

Percentage (\%) Yield of Medicinal Plants Extracts

The yield of extractable antioxidant components $(\mathrm{g} / 100 \mathrm{~g}$ of DW) from different parts of selected plants with $80 \%$ aqueous solution of methanol and $80 \%$ aqueous solution of ethanol as shown in Fig.1 varied as a function of extraction solvents and plants part used. It can be noted that maximum extract yield (33.29 g/100g of DW) was obtained from $E$. officinalis with aqueous ethanol (80\%) while aqueous methanol $(80 \%)$ gave the lowest yield $(12.72 \mathrm{~g} / 100 \mathrm{~g}$ of DW) from $C$. longa. The order of maximum percentage yield with aqueous ethanol $(80 \%)$ was found to be E. officinalis $>$ G. glabra $>N$. sativa> $M$. aquatica $>C$. longa. A significant $(p<0.05)$ variation is observed in the present research work for the percentage yield of extracts among the tested medicinal plants. As far as the efficacy of the extraction solvents is concerned, the yield of extracts $(\mathrm{g} / 100 \mathrm{~g}$ of DW) from different parts of the selected plants ranged from 12.72 to $23.38 \%$ and 14.50 to $33.29 \%$ for aqueous methanol and aqueous ethanol, respectively.

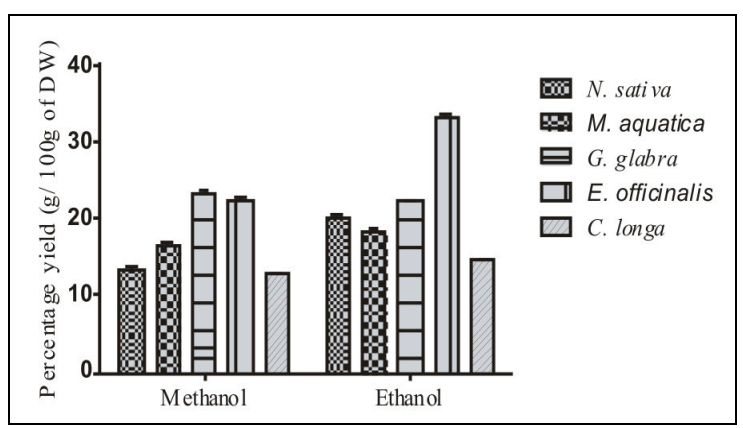

Figure 1. Percentage extract yield (g/100g of DW) from selected medicinal plants with different solvent systems. Values (mean) are average of three samples of each medicinal plant material, analyzed individually in triplicate $(n=1 \times 3 \times 3),(P<0.05)$.

Alcohols like methanol and ethanol are used as solvents for the recovery of potent antioxidant compounds from different plants tissues due to their solubility $[18,21,22]$. In 
line with the earlier reports $[18,21,22]$, the present findings showed the higher yield of extract from different plant materials with $80 \%$ aqueous solution of ethanol, which resulted in the higher efficiency of this solvent to recover bioactive compounds. Furthermore, our findings also showed a significant $(p<0.05)$ difference in the amount of extracts from selected medicinal plants, which can be linked to the recovery of various extractable antioxidant compounds into the extraction solvents.

The chemical nature of the various bioactives may also affect the percentage yield of extracts with different solvents [23]. For extracting biological components from different parts of the plants, aqueous solutions of methanol and ethanol were found to be effective solvents, but out of these two, aqueous solution of ethanol is preferred due to its non-toxic and green solvent nature. [24].

The higher percentage yield using aqueous ethanol solution in this research work is in agreement with the findings of Ahmad et al., [25], who recorded the higher percentage yield of extracts from flowers and leaves of Akk (Calotropis procera) using ethanol as solvent. The total amount of bioactives/antioxidants obtained from different plant materials depends on multiple factors like availability of components, chemical nature, and technique used to get extracts [23].

\section{Total Phenolic Contents}

Due to the potential health benefits, phenolic contents are becoming an important ingredient for functional foods and nutraceutical industries [26]. Plants derived phenolic contents can be used as natural antioxidants [27]. A large number of reports suggest that the phenolic compounds present in fruits, vegetables, and food plants contribute mainly toward their antioxidant activity [28]. In the present case, measurement of TPC in different parts of selected medicinal plant extracts was performed using FolinCiocalteau method, and the result was recorded and GAE (Gallic Acid Equivalent) [13]. TPC of different medicinal plants ranged from 16.89 to 25.06 and 13.87 to $28.63 \mathrm{~g}$ $\mathrm{GAE} / 100 \mathrm{~g}$ for extracts in aqueous methanol and aqueous ethanol, respectively (Fig. 2). A significant difference $(p<0.05)$ for TPC was noted within different plants. Aqueous ethanol extracts from some of the selected medicinal plants offered a comparatively higher amount of TPC in comparison to aqueous methanol extracts. The highest amount of TPC was shown by aqueous ethanol extract of $M$. aquatica followed by G. glabra > N. sativa > E. officinalis $>C$. longa. Total phenolics (18.47-19.04) in $N$. sativa in this research work are quite similar to the findings of Bourgou [29].

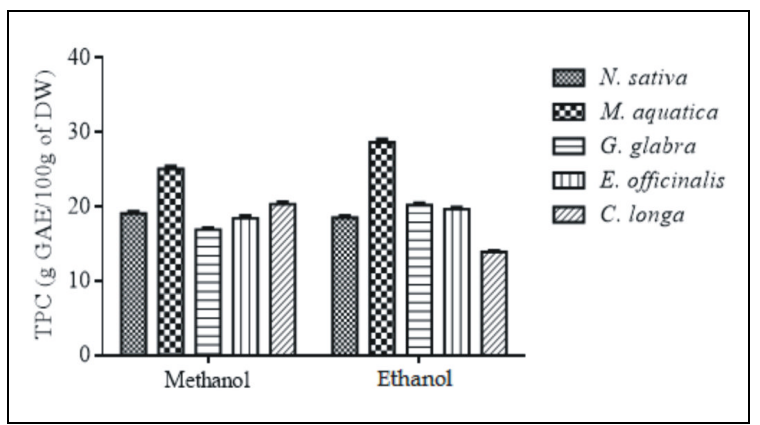

Figure 2. Total phenolic contents (g GAE/100g of DW) of extracts from selected medicinal plants with different solvent systems. Values (mean) are average of three samples of each medicinal plant material, analyzed indivi dually in tri plicate $(n=1 \times 3 \times 3),(P<0.05)$

TPC present in the extracts of different medicinal plants varied significantly $(p<0.05)$ with reference to the extracting solvent used and the part of the plant used. For the recovery of food grade biologically active compounds from plant materials, ethanol is relatively preferable due to its non-toxic nature, green nature, and good extraction efficiency [24,30]. 
Different plants showed a different amount of phenolic contents due to the fact that the presence of bioactive compounds in plants varied by plants, soil condition, maturity, and treatment after harvesting [31, 47]. For example, TPCs lower than our present values were reported in corncob, Moringa oleifera leaves, Eugenia jambolana bark, Ficus religiosa fruit, and Aloe barbadensis leaves [18,32]. Likewise, TPCs higher than our present investigations were reported in Gmelina leaf, Kigelia stem, Hibiscus fruit [6]. Moreover, some studies showed that the composition and amount of phenolics varied within the tissues at a subcellular level [33].

\section{Total Flavonoid Contents}

Total flavonoids contents (TFC) determined as Catechin Equivalent (CE) in the extracts of different parts of selected medicinal species ranged from 1.96 to 13.54 and 2.20 to $8.71 \mathrm{CE} / 100 \mathrm{~g}$ respectively (Fig 3). The amount of $\mathrm{TF}$ in tested plant extracts varied significantly $(p<0.05)$ within the species studied. Total flavonoids in aqueous ethanol extracts of different plant species were found to be higher than aqueous methanol extracts. The highest amount of TFC was noted in aqueous ethanol extract of $M$. aquatica followed by C. longa $>$ E. oficinalis $>$ N. sativa > G. glabra.

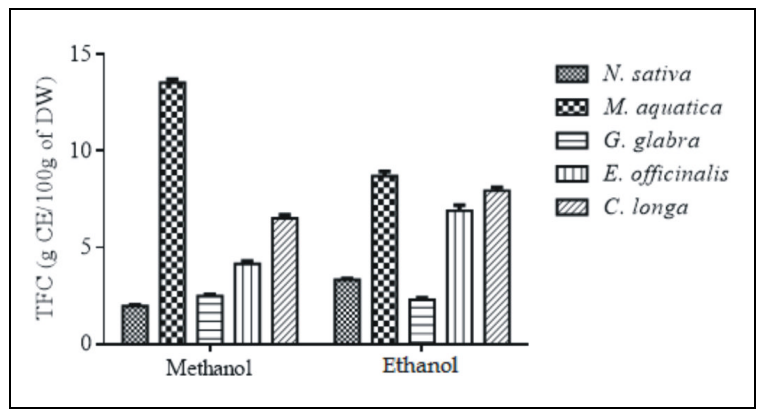

Figure 3. Total flavonoid contents (g CE / $100 \mathrm{~g}$ of DW) of extracts from selected medicinal plants with different solvent systems. Values (mean) are average of three samples of each medicinal plant material, analyzed individually in tri plicate $(n=1 \times 3 \times 3),(P<0.05)$.
The amount of total flavonoids in different parts of selected medicinal plants was found to be higher than the findings of Ebrahimzadeh et al., [34], who estimated TF in $V$. odorata leaves, B. hyrcana. In contrast, it was lower than the findings of Doss et al., [35], who determined TFC in Canavalia gladiate and Canavalia ensiformis. The ratio between total flavonoids and total phenolics varied significantly in different plant species as reported by Ribarova and Atanassova [46]; they studied the ratio between total flavonoids and total phenolics in different Bulgarian fruits and vegetables.

\section{DPPH Radical Scavenging Activity}

The free radical capturing/scavenging assay is designed on a mechanistic approach wherein the radical neutralization ability of extract is estimated colorimetrically. DPPH free radical, used in this research work, is an organic free radical that is stable, has a deep violet color, and exhibits maximum absorption within the wavelength range of 515-528 nm [36]. During this reaction, the deep violet color of DPPH is converted into yellow color as its chromophore is deactivated upon receiving a proton from plant phenolics, act as a hydrogen donor. It is a well-known fact that the DPPH free radical capturing activity varies directly with the amount of phenolics (hydrogen donors) or the extant of hydroxylation of phenolic compounds, hence antioxidant potential of plant derived extracts increases by the higher concentration of phenolics [37]. Lipid oxidation is a serious issue of the food industry and leads to loss of nutritional value of products and economic losses, and as a result of oxidative stress, free radicals are produced in biochemical processes in the body, so the antioxidant molecules slow down/interrupt oxidation process by scavenging/neutralizing free radicals or chelating the transition metals [38]. Inhibition of the chain initiation step in the process of oxidation is done by scavenging the 
reactive oxygen species and free radicals, this mode of action is considered an important antioxidant method [39].

DPPH free radical capturing ability of selected medicinal plant extracts by aqueous methanol and aqueous ethanol showed a noticeable scavenging activity in the range of 39.55 to 80.64 and 58.36 to 80.55 , respectively (Fig. 4). The aqueous ethanol extract of E. officinalis showed maximum DPPH free radical capturing activity, while methanol extracts of $C$. longa scavenged the minimum DPPH free radical.

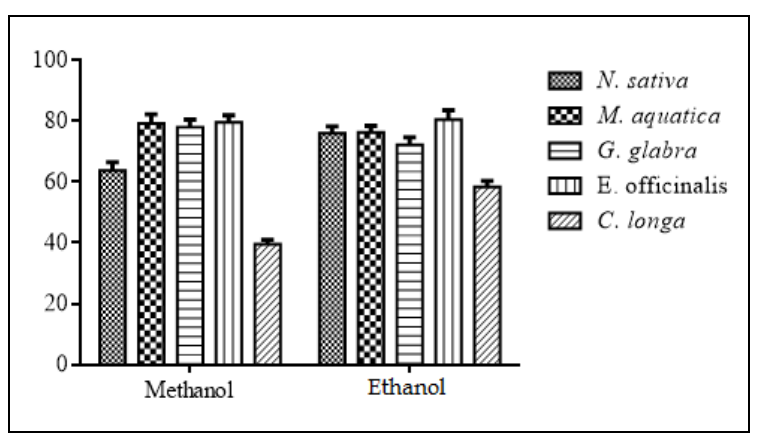

Figure 4. DPPH radical scavenging activity of extracts from selected medicinal plants with different solvent systems. Values (mean) are average of three samples of each medicinal plant material, analyzed individually in triplicate $(n=1 \times 3 \times 3),(P<0.05)$

Free radical capturing ability changed significantly $(p<0.05)$ among the selected medicinal plants. The antioxidant activity is increased due to the enhanced free radical capturing/scavenging ability with a greater amount of phenolic contents [37]. Plant phenolic compounds, being hydrogen donors, can be linked to quenching DPPH radicals. In a previous study, similar findings to our present results have been exhibited by the extract of leaves of Lantana camara (L) [40].

\section{Inhibition of Linoleic Acid Peroxidation}

The polyunsaturated fatty acids (PUFA), like linoleic acid (C18:2), produce peroxides upon oxidation. These peroxides have the ability to oxidize $\mathrm{Fe}^{2+}$ to $\mathrm{Fe}^{3+}$; and then form a complex with SCN. The intensity of the color formed by the complex can be related to the concentration, which can be noted by measuring the absorbance at the wavelength of $500 \mathrm{~nm}$. The greater the concentration of peroxides generated in the reaction mixture greater is the value of absorbance and hence results in the lower antioxidant activity [17].

The measure of prevention of lipid oxidation can be used to access the antioxidant ability of plant derived extracts. The assay was done by finding out the ability to inhibit the peroxidation of linoleic acid by thiocyanate method [17]. For the comparison of our result of antioxidant activity by the extracts of selected five medicinal plants BHT was used as a positive control.

The strength of peroxidation inhibition (\%) of different plant extracts in linoleic acid for 15 days $(360 \mathrm{~h})$ incubation period as depicted in Fig. 5 showed different levels of inhibition, ranging from 35.90 to $61.54 \%$ and 51.2 to $71.79 \%$ for an aqueous solution of methanol and aqueous solution of ethanol extracts, respectively. The inhibition of peroxidation, hence antioxidant activity, varied significantly $(p<0.05)$ among different plant extracts tested. Maximum activity was observed for extracts obtained by aqueous ethanol solution of G. glabra followed by $M$. aquatic $>N$. sativa $>$ E. officinalis $>C$. longa.

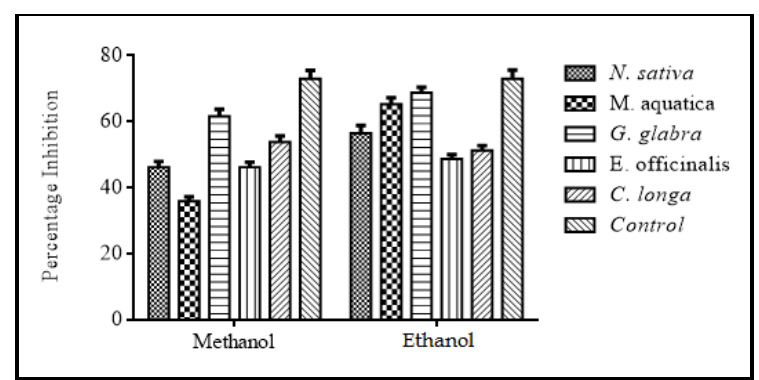

Figure 5. Percent inhibition of linoleic acid peroxi dation of extracts from selected medicinal plants with different sol vent systems. Values (mean \pm SD) are average of three samples of each medicinal plant material, analyzed individually in triplicate $(n=1 \times 3 \times 3),(P<0.05)$ 
The results of antioxidant activity of G. glabra in the present case are quite comparable with those reported for lipid peroxidation of ethanolic extracts of the same species by Visavadiya et al., [41]. Meanwhile, the present percent inhibition values are higher than the values obtained for some other potential medicinal plants such as Biebresteinia multifida, Astragalus hamosus, Salvia hydrangea, and Zataria multiflora $[3,42]$.

\section{Reducing Power}

This assay is based on the ability of electron transfer or hydrogen atom transfer via redox potential of the antioxidant extracts/compounds [39]. The reducing ability of phytochemicals present in the extracts of plants varies directly with the antioxidant activity. Thus, accessing the reducing power of extracts can be another method to measure the antioxidant activity.

The reducing power of extracts from different medicinal plants (shown in Fig. 6) was measured over the extract concentration range of $2.5-10.0 \mathrm{mg} / \mathrm{mL}$. A general trend of direct relationship between reducing power and concentration of extracts was observed. Reducing potential of extracts of different plants by both solvents ranged from 0.54 to 1.23 and 0.68 to 1.52 , respectively.

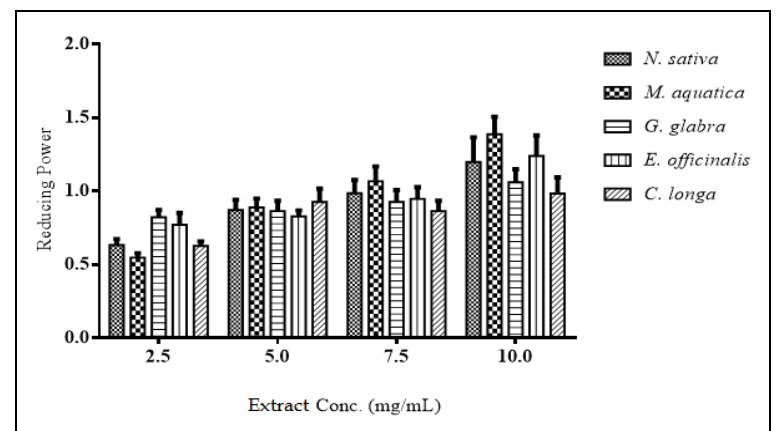

Figure 6. Reducing power of methanolic extracts from selected medicinal plants. Values (mean) are average of three samples of each medicinal plant material, analyzed individually in triplicate $(n=1 \times 3 \times 3),(P<0.05)$.
The nature of the solvent used for the extraction also have a significant $(p<0.05)$ effect on the reducing ability of the extracts. The data obtained in the present study for reducing power of extracts followed the same trends as reported in previous studies $[18,25]$.

\section{Antimicrobial Activity Disc diffusion method}

The antimicrobial activity of selected medicinal plants derived extracts were measured using disc diffusion method against a panel of bacteria (E. coli, S. aureus, and $P$. multocida strains) and fingi (A. flavus, $A$. niger, A. alternata and $G$. lucidium) and inhibition zones were measured in millimeter $(\mathrm{mm})$ (Table 1). It is clearly shown in data that ethanol extract of Nigella sativa showed strong activity ( $25 \mathrm{~mm}$ zone of inhibition) against E. coli while aqueous methanol extract of Mentha aquatic showed minimum bactericidal activity $(13 \mathrm{~mm}$ zone of inhibition). Aqueous ethanol extract of Curcuma longa showed strong activity (29 mm zone of inhibition) against A. alternata, while aqueous ethanol extracts of Mentha aquatica gave the poorest fungicidal effect against $A$. niger (12 $\mathrm{mm}$ zone of inhibition). Generally, all the plant species used in the present research work showed minimum to maximum antimicrobial activity against the panel of microorganism used.

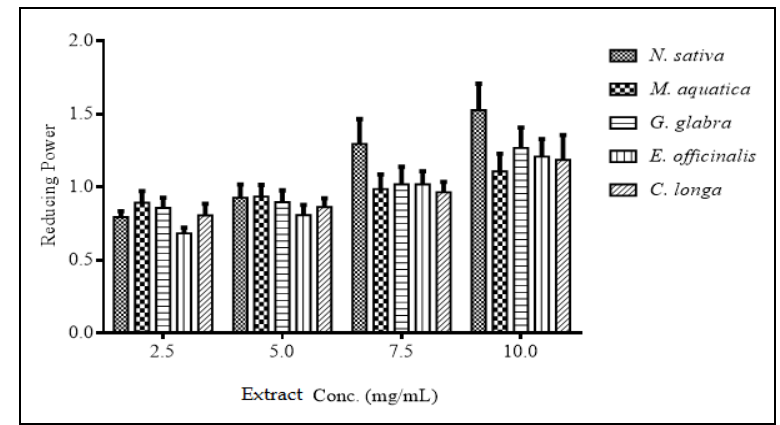

Figure 7. Reducing power of ethanolic extracts from selected medicinal plants. Values (mean) are average of three samples of each medicinal plant material, analyzed individually in triplicate $(n=1 \times 3 \times 3),(P<0.05)$. 
Table 1. Antimicrobial activity of methanol and ethanol extracts from selected medicinal plants.

\begin{tabular}{|c|c|c|c|c|c|c|}
\hline Microorganisms & & $\begin{array}{c}\text { Mentha } \\
\text { aquatica }\end{array}$ & Curcuma longa & $\begin{array}{c}\text { Emblica } \\
\text { officinalis }\end{array}$ & $\begin{array}{c}\text { Glycyrrhiza } \\
\text { glabra }\end{array}$ & Nigella sativa \\
\hline Bacteria & \multicolumn{6}{|c|}{ Zone of inhibition (mm) } \\
\hline E. coli & \multirow{3}{*}{ 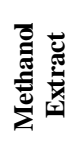 } & $13.00 \pm 0.04$ & $20.00 \pm 0.09$ & $20.00 \pm 0.02$ & $21.00 \pm 0.01$ & $14.00 \pm 0.01$ \\
\hline P. multocida & & $20.00 \pm 0.04$ & $17.00 \pm 0.01$ & $19.00 \pm 0.03$ & $17.00 \pm 0.04$ & $16.00 \pm 0.01$ \\
\hline S. aureus & & $19.00 \pm 0.01$ & $14.00 \pm 0.02$ & $22.00 \pm 0.04$ & $20.00 \pm 0.02$ & $18.00 \pm 0.05$ \\
\hline E. coli & \multirow{3}{*}{ 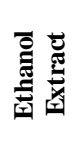 } & $21.00 \pm 0.02$ & $17.00 \pm 0.01$ & $20.00 \pm 0.01$ & $23.00 \pm 0.02$ & $25.00 \pm 0.03$ \\
\hline P. multocida & & $22.00 \pm 0.04$ & $18.00 \pm 0.01$ & $19.00 \pm 0.04$ & $22.00 \pm 0.03$ & $19.00 \pm 0.03$ \\
\hline S. aureus & & $17.00 \pm 0.02$ & $23.00 \pm 0.01$ & $20.00 \pm 0.03$ & $19.00 \pm 0.04$ & $21.00 \pm 0.02$ \\
\hline Fungi & \multicolumn{6}{|c|}{ Zone of inhibition (mm) } \\
\hline G. lucidum & \multirow{4}{*}{ 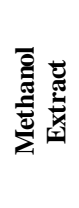 } & $22.00 \pm 0.02$ & $17.00 \pm 0.04$ & $18.00 \pm 0.02$ & $23.00 \pm 0.04$ & $16.00 \pm 0.03$ \\
\hline A. flavus & & $16.00 \pm 0.03$ & $17.00 \pm 0.02$ & $13.00 \pm 0.04$ & $14.00 \pm 0.01$ & $15.00 \pm 0.02$ \\
\hline A. niger & & $12.00 \pm 0.01$ & $16.00 \pm 0.04$ & $15.00 \pm 0.03$ & $16.00 \pm 0.04$ & $14.00 \pm 0.02$ \\
\hline A. alternate & & $18.00 \pm 0.04$ & $22.00 \pm 0.02$ & $24.00 \pm 0.01$ & $27.00 \pm 0.02$ & $19.00 \pm 0.01$ \\
\hline G. lucidum & \multirow{4}{*}{ 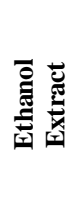 } & $20.00 \pm 0.03$ & $24.00 \pm 0.03$ & $22.00 \pm 0.01$ & $19.00 \pm 0.04$ & $18.00 \pm 0.03$ \\
\hline A. flavus & & $16.00 \pm 0.02$ & $15.00 \pm 0.01$ & $19.00 \pm 0.04$ & $17.00 \pm 0.02$ & $14.00 \pm 0.01$ \\
\hline A. niger & & $17.00 \pm 0.03$ & $19.00 \pm 0.03$ & $18.00 \pm 0.01$ & $20.00 \pm 0.01$ & $16.00 \pm 0.04$ \\
\hline A. alternate & & $21.00 \pm 0.01$ & $29.00 \pm 0.02$ & $20.00 \pm 0.01$ & $23.00 \pm 0.04$ & $25.00 \pm 0.01$ \\
\hline
\end{tabular}

Note: Data are the mean of three independent replicates, rounded off to near whole numbers. Values are mean \pm SD of three samples analyzed individually in triplicate at $p<0.05$.

The difference in the antimicrobial activity of selected parts of medicinal plant extracts may be due to the difference in the composition of extracts by different plants. Previous studies also reported that the biological activity of the extracts obtained from different plants is directly affected by the change in their chemical composition $[43,45]$. The antimicrobial activities of the plant species are due to the presence of certain bioactive phytochemicals such as ascorbic acid, saponins, flavonoids, betulinic acid, phenolic acids and glycosides. Alkaloids are the class of strong antibacterial agents, and Curcuma longa contains alkaloids such as coclaurine, frangufoline, norisoboldine, isoboldine, iusirine, asimilobine, and iusiphine. The Antimicrobial potential of roots of Glycyrrhiza glabra was reported less than our present findings by [44].

\section{Minimum inhibitory concentration (MIC)}

This is the concentration of extracts that can completely limit the growth capability of microorganisms. For measuring the minimum inhibitory concentration $(\mathrm{mg} / \mathrm{mL})$ of extracts, the microdilution broth susceptibility assay was used [19]. Table 2 revealed that aqueous ethanol extract of Curcuma longa showed the lowest minimum inhibitory concentration $(12 \mathrm{mg} / \mathrm{mL})$, indicating its best activity against $S$. aureus while aqueous methanol extract of Mentha aquatica had the highest minimum inhibition concentration (67 $\mathrm{mg} / \mathrm{mL}$ ), showing the weakest activity against E. coli. Aqueous ethanol extract of Curcuma longa exhibited the lowest minimum inhibition concentration $(11 \mathrm{mg} / \mathrm{mL})$, showing greater effectiveness against $A$. alternate, while aqueous methanol extract of Mentha aquatica had a higher minimum inhibition concentration $(83 \mathrm{mg} / \mathrm{mL})$, indicating its weakest against $A$. niger. 


\section{Conclusion}

Based on the results of different assays, it was noted that aqueous ethanol extracts from selected parts of different medicinal plants exhibited relatively better antioxidant activity linked to appreciable amounts of TP and TF in these extracts. All the tested extracts showed appreciable but variable antimicrobial activity. In general, extraction of antioxidant / antimicrobial agents by different solvents from selected parts of medicinal plants yielded extracts of different chemical nature and hence showed different biological activities. This difference can be due to the availability of various components depending upon the solvent used for extraction and the part of the plant used. Therefore, it can be concluded that a suitable extraction process must be selected to recover a good yield of powerful antioxidant compounds from the selected parts of the subject medicinal plants. Additional detailed analysis is recommended to characterize individual bioactives and study the structure-activity relationship of these compounds and in vivo assessment of biological activities trials of the major component in different parts of the selected medicinal plants.

\section{Conflict of Interest}

The authors state that they have no conflict of interest.

\section{References}

1. N. Ozsoy, A. Can, R. Yanardag and N. Akev, Food Chem., 110 (2008) 571. https://doi.org/10.1016/j.foodchem.2008.02. $\underline{037}$

2. S. Gorinstein, U. Shalev, K. Yamamoto, H. Leontowicz, A. Lojek, M. Leontowicz, M. C`1z, I. Goshev and S. Trakhtenberg, Biosci. Biotech. Biochem., 67 (2003) 907Á.

https://scholar.google.com/scholar?hl=e n\&as_sdt $=0 \% 2 \mathrm{C} 5 \& \mathrm{q}=\mathrm{S} .+$ Gorinstein $\% 2$ C+U.+Shalev\% 2C+K.+Yamamoto\%2C + H.+Leontowicz\% 2C+A.+Lojek\% 2C+ M.+Leontowicz\%2C+M.+C\% CB\%87\% C4\% B1z\%2C+I.+Goshev+and+S.+Trak htenberg.+Biosci.+Biotech.+Biochem.\% 2C+67+\%282003\% 29+907\%C 3\%81.\&b tnG=

3. E. Souri, G. Amin, H. Farsam, H. Jalalizadeh and S. Barezi, Iran. J. Pharm. Res., 7(2) (2008) 149.

doi: 10.22037/IJPR.2010.758

4. T. Gull, F. Anwar, B. Sultana, M.A.C. Alcayde and W. Nouman, Ind. Crops Prod., 67 (2015) 81. https://doi.org/10.1016/j.indcrop.2014.1 2.059

5. G. Muhammad, M.A. Hussain, F, Anwar, M. Ashraf and A.H. Gilani, Phytother. Res., 29 (2015) 1.

https://doi.org/10.1002/ptr.5222

6. V.R. Patel, P.R. Patel and S.S. Kajal, Adv. Biol. Res., 4 (2010) 23.

https://pdfs. semanticscholar.org/9500/9c 2bd5c72815b3099bad838f2f3e50468636 .pdf

7. A.I. Hussain, F. Anwar, T. Iqbal and I.A. Bhatti, Pak. J. Bot., 43(2) (2011) 1315. http://www.pakbs.org/pjbot/PDFs/43(2)/ PJB43(2)1315.pdf

8. N. Mimica-Dukic, B. Bozin, M. Sokovic, B. Mihajlovic and M. Matavulj, Planta Medica., 69 (2003) 413.

doi: $10.1055 / \mathrm{s}-2003-39704$

9. J. E. Pizorrno and M. T. Murray, Textbook of Natural Medicine, (2nd Ed.) London, Churchill Livingstone, (1999) 689.

https://www.elsevier.com/books/textboo k-of-natural-medicine/pizzorno/978-14377-2333-5

10. L. Anila and N. R, Vijayalakshm, Food Chem., $83 \quad$ (2003) 569. https://doi.org/10.1016/S03088146(03)00155-9 
11. G. G. Konovalova, A. K. Tikhaze and V. Z. Lankin, Bull. Exp. Biol. Med., 130 (2000) 658. https://doi.org/10.1007/BF02682098

12. M. Burits and F. Bucar, Phytother. Res., 14 (2000) 323.

https://doi.org/10.1002/1099-

1573(200008)14:5<323::AID-

PTR621>3.0.CO;2-Q

13. A. Chaovanalikit and R. E. Wrolstad, Food Sci., 69 (2004) 67.

https://doi.org/10.1111/j.1365-

2621.2004.tb17858.x

14. V. Dewanto, X. Wu, K. K. Adom and R.

H. Liu, J. Agric. Food Chem., 50 (2002)

3010.

https://doi.org/10.1021/jf0115589

15. B. Bozin, N. Mimica-Dukic, N. Simin and G. Anackov, J. Agric. Food Chem., 54 (2006) 1822.

https://doi.org/10.1021/if051922u

16. S. Iqbal, M. I. Bhanger and F. Anwar, Food Chem., 93 (2005) 265.

https://doi.org/10.1016/j.foodchem.2004. 09.024

17. G. C. Yen, P. D. Duh and D. Y. Chaung, Food Chem., 70 (2000) 437.

https://doi.org/10.1016/S03088146(00)00108-4

18. B. Sultana, F. Anwar and R. Przybylski, Food Chem., 104 (2007) 1106.

https://doi.org/10.1016/j.foodchem.2007. $\underline{01.019}$

19. NCCLS, National Committee for Clinical Laboratory Standards, M 100S9 (NCCLS: Wayne, P.A.) (2004). https://www.scirp.org/(S(i43dyn45teexjx $455 \mathrm{qlt} 3 \mathrm{~d} 2 \mathrm{q})) /$ reference/ReferencesPaper S.aspx?ReferenceID $=1145440$

20. R. G. D. Steel, J. H. Torrie and D. A. Dicky, Principles and Procedures of Statistics (McGraw Hill Book Inc.) New York, (1997).

https://scholar.google.com/scholar?hl=e n\&as_sdt=0\%2C5\&q=20.\%09R.+Steel+ and+J.H.+Torrie $\% 2 \mathrm{C}+$ Principles+and $+\mathrm{P}$ rocedures + of + Statistics $+\% 28 \mathrm{McGraw}+$ Hill+Book+Inc.\%29+New+York\%2C+ $\% 281997 \% 29 \& b \operatorname{bin}=$

21. S. Zahoor, F. Anwar, T. Mehmood, B. Sultana and R. Qadir, J. Chil. Chem. Soc., 61 (2016) 2884.

http://dx.doi.org/10.4067/S071797072016000200007

22. G. Shabir, F. Anwar, B. Sultana, Z. M. Khalid, M. Afzal, Q. M. Khan and M. Ashrafuzzaman, Molecules, 16 (2011) 7302.

https://doi.org/10.3390/molecules160973 $\underline{02}$

23. B. Hsu, I. M. Coupar and K. Ng, Food Chem., 98 (2006) 317.

https://doi.org/10.1016/j.foodchem.2005. $\underline{05.077}$

24. Y. T. Tung, J. H. Wu, Y. H. Kuo and S. T. Chang, Bioresour. Technol., 98 (2007) 1120.

https://doi.org/10.1016/j.biortech.2006.0 4.017

25. N. Ahmad, F. Anwar, S. Hameed and M. C. Boyce, J. Med. Plants Res., 5 (2011) 4879.

https://academicjournals.org/journa1/JM PR/article-abstract/6E1B38A26272

26. A. Wojdyło, J. Oszmiański and R. Czemerys, Food chem., 105 (2007) 940. https://doi.org/10.1016/j.foodchem.2007. $\underline{04.038}$

27. J. M. Awika, L.W. Rooney, X. Wu, R. L. Prior and L. Cisneros-Zevallos, $J$. Agric. Food Chem., 51 (2003) 6657. https://doi.org/10.1021/jf034790i

28. V. Katalinic, M. Milos, T. Kulisic and M. Jukic, Food Chem., 94 (2006) 550. https://doi.org/10.1016/j.foodchem.2004. $\underline{12.004}$

29. S. Bourgou, R. Ksouri, A. Bellila, I. Skandrani, H. Falleh and B. Marzouk, $C$. R. Biol., 331 (2008) 48. https://doi.org/10.1016/j.crvi.2007.11.001

30. F. Karadeniz, H.S. Burdurlu, N. Koca and Y. Soyer, Turk. J. Agric. For., 29 (2005) 297. 
http://journals.tubitak.gov.tr/agriculture/ abstract.htm?id=7822

31. E. H. Jeffery, A. F. Brown, A. C. Kurilich, A. S. Keck, N. Matusheski, B. P. Klein and J. A. Juvik, J. Food Comp. Anal., 16 (2003) 323. https://doi.org/10.1016/S08891575(03)00045-0

32. B. Sultana, F. Anwar and M. Ashraf, Molecules, 14 (2009) 2167.

https://doi.org/10.3390/molecules140621 $\underline{67}$

33. R. Randhir, Y. T. Lin and K. Shetty, Asia Pac. J. Clin. Nutr., 13 (2004) 295. https://www.ncbi.nlm.nih.gov/pubmed/1 5331344

34. M. A. Ebrahimzadeh, S. M. Nabavi, F. Bahramian and A. R. Bekhradnia, Pak. J. Pharm. Sci., 23 (2010) 29. https://pdfs.nutramedix.ec/Ezov\%20\%20Antioxidant\%20(Free\%20Rad).pdf

35. A. Doss, M. Pugalenthi, D. Rajendrakumaran and V. Vadive. Asian J. Exp. Biol. Sci., 1 (2010) 700. https://scholar.google.com/scholar?hl=e n\&as_sdt $=0 \% 2 \mathrm{C} 5 \& \mathrm{q}=\mathrm{A} .+\operatorname{Doss} \% 2 \mathrm{C}+\mathrm{M}$. + Pugalenthi\%2C+D.+Rajendrakumaran +and+V.+Vadive.+Asian+J.+Exp.+Biol. + Sci.\% 2C+1\%283\%29+\%282010\%29+ 700\&btnG $=$

36. A. Abbas, F. Anwar and N. Ahmad, $J$. Essent. Oil-Bear. Plants, 20 (2017) 95. https://doi.org/10.1080/0972060X.2017. 1280418

37. C. Sánchez-Moreno, J. A. Larrauri and F. Saura-Calixto, Food Res. Int., 32 (1999) 407.

https://doi.org/10.1016/S0963-

9969(99)00097-6

38. G. Oboh, R. L. Puntel and J. B. T. Rocha, Food Chem., 102 (2007) 178. https://doi.org/10.1016/j.foodchem.2006. $\underline{05.048}$

39. K. Dastmalchi, H. D. Dorman, M. Koşar and R. Hiltunen, Food Sci. Technol., 40 (2007) 239.

https://doi.org/10.1016/j.lwt.2005.09.019
40. L. Siracusa, A. Saija, M. Cristani, F. Cimino, M. D'Arrigo, D. Trombetta, F. Rao and G. Ruberto, Fitoterapia, 82 (2001) 546.

https://doi.org/10.1016/j.fitote.2011.01.0 $\underline{09}$

41. N. P. Visavadiya, B. Soni and N. Dalwadi, Int. J. Food Sci. Nutri., 60 (2009) 135.

https://doi.org/10.1080/09637480902877 $\underline{998}$

42. M. Gulluce, F. Sahin, M. Sokmen, H. Ozer, D. Daferera, A. Sokmen, M. Polissiou, A. Adiguzel and H. Ozkan, Food Chem., 103 (2007) 1449.

https://doi.org/10.1016/j.foodchem.2006. $\underline{10.061}$

43. O. Yesil-Celiktas, P. Nartop, A. Gurel, E. Bedir and F. Vardar-Sukan, J. Plant Physiol., 164 (2007) 1536.

https://doi.org/10.1016/j.jplph.2007.05.0 13

44. V. K. Gupta, A. Fatima, U. Faridi, A. S. Negi, K. Shanker, J. K. Kumar, N. Rahuja, S. Luqman, B.S. Sisodia, D. Saikia and M. P. Darokar, $J$. Ethnopharmacol., 116 (2008) 377. https://doi.org/10.1016/j.jep.2007.11.037

45. F. Anwar, A. Abbas, T. Mehmood, A.H. Gilani and N.U. Rehman, Phytother. Res., 33 (2019) 2548. https://doi.org/10.1002/ptr.6423

46. D. Marinova, F. Ribarova and M. Atanassova, J. Univ. Chem. Technol. Metall., 40 (2005) 255.

https://dl.uctm.edu/journal/node/j20053/Marinova.pdf

47. N. Ahmad, Y. Zuo, X. Lu, F. Anwar and S. Hameed, Food Chem., 190 (2016) 80. https://doi:10.1016/j.foodchem.2015.05. $\underline{077}$ 